\title{
Article
}

\section{Low-Temperature Growth of ZnO Nanowires from Gravure-Printed ZnO Nanoparticle Seed Layers for Flexible Piezoelectric Devices}

\author{
Andrés Jenaro Lopez Garcia ${ }^{1,+}$, Giuliano Sico ${ }^{2, \dagger}$, Maria Montanino ${ }^{2,+}$, Viktor Defoor ${ }^{1}$, Manojit Pusty ${ }^{1}{ }^{1}$, \\ Xavier Mescot ${ }^{1}$, Fausta Loffredo ${ }^{2}$, Fulvia Villani ${ }^{2}$, Giuseppe Nenna ${ }^{2, *}$ and Gustavo Ardila ${ }^{1, * \mathbb{D}}$ \\ 1 University Grenoble Alpes, University Savoie Mont Blanc, CNRS, Grenoble INP, IMEP-LaHC, \\ F-38000 Grenoble, France; andres-jenaro.lopez-garcia@grenoble-inp.fr (A.J.L.G.); \\ viktor.defoor@grenoble-inp.fr (V.D.); manojit.pusty@grenoble-inp.fr (M.P.); \\ xavier.mescot@grenoble-inp.fr (X.M.) \\ 2 ENEA, Italian National Agency for New Technologies, Energy and Sustainable Economic Development, \\ Portici Research Centre, P.le E. Fermi 1, Portici, I-80055 Naples, Italy; giuliano.sico@enea.it (G.S.); \\ maria.montanino@enea.it (M.M.); fausta.loffredo@enea.it (F.L.); fulvia.villani@enea.it (F.V.) \\ * Correspondence: giuseppe.nenna@enea.it (G.N.); $\operatorname{ardilarg@minatec.grenoble-inp.fr~(G.A.);~}$ \\ Tel.: +33-456-529-532 (G.A.) \\ + These authors contributed equally to the work.
}

check for updates

Citation: Garcia, A.J.L.; Sico, G.; Montanino, M.; Defoor, V.; Pusty, M.; Mescot, X.; Loffredo, F.; Villani, F.; Nenna, G.; Ardila, G. Low-

Temperature Growth of $\mathrm{ZnO}$

Nanowires from Gravure-Printed ZnO Nanoparticle Seed Layers for Flexible Piezoelectric Devices. Nanomaterials 2021, 11, 1430. https:/ / doi.org/10.3390/nano11061430

Academic Editor: Matt Cole

Received: 19 April 2021

Accepted: 19 May 2021

Published: 28 May 2021

Publisher's Note: MDPI stays neutral with regard to jurisdictional claims in published maps and institutional affiliations.

\section{Copyright: (c) 2021 by the authors.} Licensee MDPI, Basel, Switzerland. This article is an open access article distributed under the terms and conditions of the Creative Commons Attribution (CC BY) license (https:// creativecommons.org/licenses/by/ $4.0 /)$.

\begin{abstract}
Zinc oxide $(\mathrm{ZnO})$ nanowires (NWs) are excellent candidates for the fabrication of energy harvesters, mechanical sensors, and piezotronic and piezophototronic devices. In order to integrate $\mathrm{ZnO}$ NWs into flexible devices, low-temperature fabrication methods are required that do not damage the plastic substrate. To date, the deposition of patterned ceramic thin films on flexible substrates is a difficult task to perform under vacuum-free conditions. Printing methods to deposit functional thin films offer many advantages, such as a low cost, low temperature, high throughput, and patterning at the same stage of deposition. Among printing techniques, gravure-based techniques are among the most attractive due to their ability to produce high quality results at high speeds and perform deposition over a large area. In this paper, we explore gravure printing as a cost-effective high-quality method to deposit thin $\mathrm{ZnO}$ seed layers on flexible polymer substrates. For the first time, we show that by following a chemical bath deposition (CBD) process, $\mathrm{ZnO}$ nanowires may be grown over gravure-printed $\mathrm{ZnO}$ nanoparticle seed layers. Piezo-response force microscopy (PFM) reveals the presence of a homogeneous distribution of Zn-polar domains in the NWs, and, by use of the data, the piezoelectric coefficient is estimated to be close to $4 \mathrm{pm} / \mathrm{V}$. The overall results demonstrate that gravure printing is an appropriate method to deposit seed layers at a low temperature and to undertake the direct fabrication of flexible piezoelectric transducers that are based on $\mathrm{ZnO}$ nanowires. This work opens the possibility of manufacturing completely vacuum-free solution-based flexible piezoelectric devices.
\end{abstract}

Keywords: piezoelectric sensor; mechanical energy harvesting; nanogenerator chemical synthesis; gravure printing; flexible electronics

\section{Introduction}

Flexible piezoelectric transducers make the development of innovative devices possible, especially in the energy and sensor fields [1]. Several piezoelectric materials have been studied and integrated into flexible substrates, including organic materials, such as poly(vinylidene fluoride) (PVDF) [2] and its co-polymers [3-5]; inorganic materials, like lead zirconate titanate (PZT) [6], potassium sodium niobate (KNN) [7], lead magnesium niobate-lead titanate (PMN-PT) [8], barium titanate $\left(\mathrm{BaTiO}_{3}\right)$ [9], zinc stannate $\left(\mathrm{ZnSnO}_{3}\right)$ [10], and bismuth ferrite $\left(\mathrm{BiFeO}_{3}\right)$ [11]; and semiconductors like zinc oxide $(\mathrm{ZnO})$ in the shape of nanowires (NWs) [12,13]. Among those materials, $\mathrm{ZnO}$ has attracted a 
great deal of attention because it is biocompatible, abundant, and sustainable, making it interesting for future applications while reducing the use of critical and toxic materials [14]. In particular, $\mathrm{ZnO}$ NWs have been widely used in different applications related to the conversion of mechanical energy into electricity at the nanometric scale. Some advantages of these NWs, compared to the bulk counterpart, are the ability to withstand high deformation values without fracturing [15-17], high values for the Young's modulus [18,19], and high values for the piezoelectric coefficient [20], as well as a high surface-to-volume ratio that allows enhanced piezoelectric responses thanks to Fermi-level pinning [21].

$\mathrm{ZnO}$ can exist in different miniaturized forms, like quantum dots, nanorods, nanowires, nanotubes, nanosheets, nanobelts, nanocones, and twinned disk structures [22]. The ability to form different shapes in miniature sizes, along with a high surface charge density, polarity, and orientation enables $\mathrm{ZnO}$ nanostructures to display various applications in the fields of gas sensing, energy storage, energy harvesting, photocatalysis, flexible electronics, optoelectronics, and environmental waste treatment, etc. The high surface area of $\mathrm{ZnO}$ NWs promotes greater interfacial adsorption and diffusion, which enhances their physical and chemical properties. $\mathrm{ZnO}$ has a wide band gap of $3.37 \mathrm{eV}$, which is one of the highest in the II-IV semiconductor metal oxides, and also has a large excitation binding energy of $60 \mathrm{meV}$ [23].

These superior properties make $\mathrm{ZnO}$ NWs an interesting material to be adopted in the high-tech renewable energy field for the development of energy conversion or storage devices, as $\mathrm{ZnO}$ NWs meet the requirements for power and energy density [24]. Also, the low cost of fabrication, negligible emission of pollutants, and the possibility of enhancing energy conversion efficiency make ZnO NW-based devices economically viable for industrial production $[25,26]$.

The first energy harvesting device based on $\mathrm{ZnO}$ NWs (then referred to as a nanogenerator-NG) was demonstrated in 2006 by Wang et al. [27]. Since then, a number of NG devices with different structures that are grown on flexible or rigid substrates have been investigated. Recently, in the field of flexible electronics, a great deal of effort has been focused on flexible NG devices, which can be used while experiencing bending [28-30] or compressive [31-35] forces in applications like material-based flexible electronic skins [36] or as nanocomposite-based sensors [37].

Chemical bath deposition (CBD) is a particularly popular method to grow piezoelectric nanostructures due to its ease of implementation, support to scale production, and moderate processing temperatures $[33,38,39]$. With low processing temperatures, the method is suitable for the use of flexible plastic substrates. Usually, the substrate is covered by a thin seed layer to promote growth and lower the thermodynamic nucleation barrier [40]. Once the seed layer is deposited, the substrates are immersed in a supersaturated growth solution at a moderate temperature for several hours. Using this technique, ZnO NWs or nanorods (NRs) have been grown over metallic [41-43] and polymeric materials [30,44,45], depending on the type of $\mathrm{ZnO}$ seed layer deposition. In this work, zinc nitrate hexahydrate $\left(\mathrm{Zn}\left(\mathrm{NO}_{3}\right)_{2} \cdot 6 \mathrm{H}_{2} \mathrm{O}\right)$ and hexamethylenetetramine $\left(\left(\mathrm{CH}_{2}\right)_{6} \mathrm{~N}_{4}\right)$ are used as precursors for the synthesis of ZnO NWs using the CBD process. Hexamethylenetetramine (HMTA) is a popular reagent that is used as a hydroxide anion $\left(\mathrm{OH}^{-}\right)$precursor for $\mathrm{ZnO}$ synthesis [46].

To date, a large variety of techniques are used to obtain $\mathrm{ZnO}$ seed layers, such as RF sputtering, atomic layer deposition (ALD), spray pyrolysis, chemical vapor deposition, and wet chemical synthetic routes, including spin and dip coatings $[47,48]$; however, most of them are confined to a laboratory scale and require an additional procedure for preparing patterned layers through expensive and complex processes such as photolithography and etching [49]. Moreover, the typical synthetic routes usually require high temperature annealing post-treatment for improving the crystallinity of the $\mathrm{ZnO}$ seeds, thus excluding polymers from the choice of flexible substrates [50-52].

On the other hand, there has been an increasingly pressing demand for easy and cost-effective methods to prepare $\mathrm{ZnO}$ patterned seed layers at low temperatures $[49,53]$, which is essential for the use of plastic substrates. 
In the last decade, conventional printing processes have been highly regarded as additive techniques for easy, fast, and low-cost thin film deposition at ambient conditions $[54,55]$. Using these techniques, patterning is carried out simultaneously with the deposition, thus substantially reducing energy, time, and material consumption [56]. In addition, the typical low temperatures of solution processes make printing compatible with most flexible substrates [55,57]. Among printing techniques, gravure techniques are widely employed in many fields and applications thanks to the ability to couple high throughput and high quality $[58,59]$. Recently, gravure printing has been proven to support the production of uniform large-scale nanoparticulate $\mathrm{ZnO}$ thin films on flexible plastic substrates [60]. The quality of the deposited films is so high that it successfully allows subsequent $\mathrm{ZnO}$ sintering through an innovative method at a very low temperature and in pressure less conditions [61]. Several printing techniques have been used to deposit $\mathrm{ZnO}$ seed layers for the subsequent growth of $\mathrm{ZnO} N W s$, although none of the reports show piezoelectric measurements with the grown NWs [57]. Furthermore, to the best of our knowledge, there have been no reports on the growth of $\mathrm{ZnO} N W$ s from layers deposited by gravure printing.

Gravure printing techniques rely on the direct transfer of a low-viscosity ink (1-100 mPas) from the micro-engraved cells of a cylinder to a flexible substrate by the pressure of a counter cylinder. This process can be considered as a sequence of subprocesses (inking, doctoring, transfer, spreading, and drying, as shown in Figure 1a-d) [60]. Essentially, at the microscopic level, the fluid dynamics of the gravure printing process are governed by the balance between viscous and surface tension forces, where the latter are the driving force [62].

a)

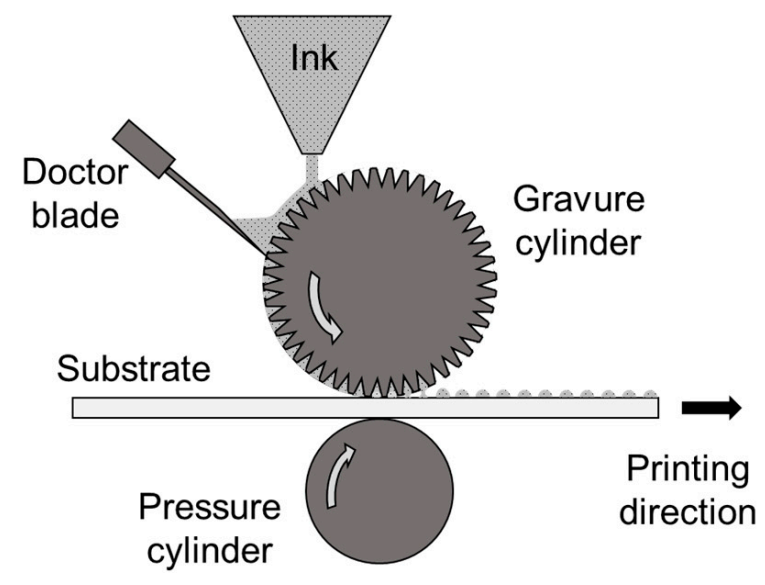

b)

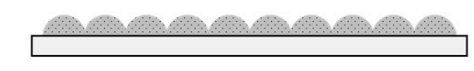

c)

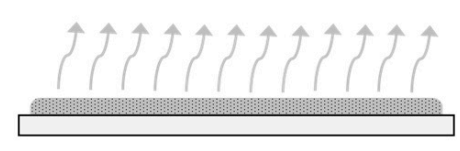

d)

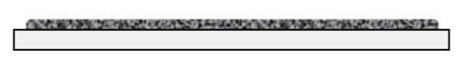

e)

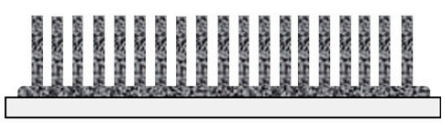

Figure 1. Fabrication process of $\mathrm{ZnO}$ seed layers by gravure printing and subsequent $\mathrm{NW}$ growth. The gravure printing process can be divided in the following steps: (a) inking, doctoring, and transfer; (b) spreading; (c) drying; (d) production of the final solid thin film. (e) The final growth of $\mathrm{ZnO}$ NWs is performed via low-temperature CBD.

In this study, gravure printing with crystalline $\mathrm{ZnO}$ nanoparticles (NPs) was attempted for the first time to produce a seed layer for $\mathrm{ZnO} N W$ growth (Figure 1e) from the perspective of flexible piezoelectric devices manufacturing. Using crystalline NPs as starting material allows the elimination of the thermal post-annealing step, making the process easier, time-effective, and compatible with polymeric substrates. Two morphologies of the seed layer were also produced (i.e., nanoparticulate and sintered) to investigate their influence on the density, the diameter, and the orientation of NW growth. The NWs grown from the gravure-printed seed layers were also compared with $\mathrm{ZnO}$ NWs grown from a seed layer deposited by ALD on a silicon substrate as a reference. 
Piezoelectric properties, including the amplitude of the piezo-response and the phase of the grown NWs, were measured with the different samples via piezo-response force microscopy (PFM).

\section{Experiments}

\subsection{Seed Layer Deposition}

A ZnO NP colloidal suspension (Sigma-Aldrich, St. Luis, MO, USA, particle size $<130 \mathrm{~nm}$ ) was used to prepare an ink, diluting the commercial suspension with ethanol (final concentration $8 \mathrm{wt} \%$ ), for printing seed layers of a $55 \pm 6 \mathrm{~nm}$ size onto a commercial indium tin oxide (ITO)/poly(ethylene terephthalate) (PET) $(150 \mathrm{~nm} / 125 \mu \mathrm{m})$ substrate $\left(2 \times 1.5 \mathrm{~cm}^{2}\right)$ acquired from DuPont Teijin Films, Luxembourg.

Printing was performed using a lab-scale gravure printer (IGT G1-5, Amsterdam, the Netherland) equipped with a cylinder with a line density of 70 lines $/ \mathrm{cm}$, stylus angle of $120^{\circ}$, screen angle of $53^{\circ}$, and cell depth of $30 \mu \mathrm{m}$. All prints were performed in air at room temperature on corona-treated substrates. After preliminary tests, the best printing conditions were found to be a printing force of $500 \mathrm{~N}$ at a speed of $60 \mathrm{~m} / \mathrm{min}$. After printing, the samples were dried at $100{ }^{\circ} \mathrm{C}$ for one hour. The thickness of the dried printed layers above reported was investigated by an interferometry-based optical profilometer (Talysurf CCI HD, Taylor Hobson, Leicester, UK).

A set of $\mathrm{ZnO}$ NP printed samples were exposed to the vapor of $1 \mathrm{M}$ acetic acid aqueous solutions for $4 \mathrm{~h}$ in a closed oven at $50^{\circ} \mathrm{C}$ for inducing chemical bonds among the particles up to the sintering, as reported elsewhere [61].

A 40-nm-thick $\mathrm{ZnO}$ seed layer was also deposited on an ITO/Si $(166 \mathrm{~nm} / 375 \mu \mathrm{m})$ substrate $\left(1.5 \times 1.5 \mathrm{~cm}^{2}\right)$ by ALD at $250{ }^{\circ} \mathrm{C}$ as previously reported [33]. These samples were prepared as references for the growth of $\mathrm{ZnO}$ NWs.

\subsection{Growth of Nanowires}

All ZnO NWs were grown under identical conditions by CBD. Samples grown on $\mathrm{Si} / \mathrm{ITO}$ substrates were firstly cleaned with acetone, ethanol, and DI water in an ultrasonic bath for $5 \mathrm{~min}$ and dried with an $\mathrm{N}_{2}$ gun. For the seed layers prepared by gravure printing, the acetone and ethanol washing steps were omitted. Hexamethylenetetramine $\left(\left(\mathrm{CH}_{2}\right)_{6} \mathrm{~N}_{4}\right.$, Sigma-Aldrich) and zinc nitrate hexahydrate $\left(\mathrm{Zn}\left(\mathrm{NO}_{3}\right)_{2} \cdot 6 \mathrm{H}_{2} \mathrm{O}\right.$, Sigma-Aldrich, St. Luis, $\mathrm{MO}$, USA) were dissolved in equimolar $(50 \mathrm{mM})$ ratios in $150 \mathrm{~mL}$ of DI water at room temperature. The growth solution was stirred for $20 \mathrm{~min}$ at $1000 \mathrm{rpm}$ and later put to rest for $40 \mathrm{~min}$ before decanting the clear solution into glass bottles. The substrates were fixed on cleaned glass slides with Kapton tape before being immersed face-down into the growth solution. The hydrothermal growth was carried out in an oven at $85^{\circ} \mathrm{C}$ for $16 \mathrm{~h}$. Later, the substrates were rinsed with DI water and dried with an $\mathrm{N}_{2}$ gun before being stored for surface characterization.

\subsection{Structural Property Measurement}

The printed films were morphologically characterized by atomic force microscopy (AFM) and scanning electron microscopy (SEM). AFM analysis was carried out using the Veeco Dimension Digital Instruments Nanoscope IV, New York, NY, USA.

Plainview, NY 11803 apparatus in the tapping mode configuration. For the SEM investigations of the gravure films, a field emission scanning electron microscope (FEGSEM, Leo 1530 Gemini by Zeiss, Oberkochen, Germany) was used with an operating voltage of 7-9 $\mathrm{kV}$.

Raman spectroscopy was carried out by a Renishaw InVia Reflex (Renishaw, Torino, IT) spectrometer selecting the laser wavelength of $514.5 \mathrm{~nm}$ (laser power of $100 \%$ ) and an objective of $50 \times$ for magnification. The investigated wavelength range was $300-800 \mathrm{~cm}^{-1}$. For each measurement, 30 subsequent accumulations and an exposure time of $10 \mathrm{~s}$ were set. For each type of sample, ten measurements were taken in order to verify their homogeneity. 


\subsection{Piezoelectric and Polarity Measurement}

A Bruker Dimension Icon (Santa Barbara, CA, USA) atomic force microscope instrument was used to carry out the PFM measurements on the ZnO NWs. A PtSi noncontact high-resonance frequency $(\mathrm{NCH})$ tip with a high spring constant value (range values among $43-50 \mathrm{~N} / \mathrm{m}$ ) was used in the measurements. The PtSi-NCH tip was chosen to perform the PFM measurement as it allows a reduction of the electrostatic force involved in the piezoelectric signal $[63,64]$. The applied AC bias was fixed at $5 \mathrm{~V}$, and the frequency was kept at $14 \mathrm{kHz}$ to avoid any electrostatic contribution (typically above $50 \mathrm{kHz}$ ) as shown in the amplitude and phase vs. frequency plots (see Figure S1). To avoid collisions and lateral bending of the vertically grown NWs with the AFM tip, the classical contact mode PFM was not used in this study. Instead, the DataCube mode was used to measure the amplitude and phase (see the details in the Supplementary Material, including Figures S2 and S3).

\section{Results and Discussion}

In this work, gravure printing was investigated regarding the deposition of $\mathrm{ZnO}$ seed layers for the subsequent growth of NWs. On the base of a previous study [60], it was possible to obtain a very smooth, continuous, and homogeneous thin film of nanoparticulate $\mathrm{ZnO}$ seeds printed onto an ITO-coated PET substrate (see details in the Supplementary Material, including Table S1 and Figure S4). After printing, some of the printed samples were exposed to a vapor annealing sintering treatment at a very low temperature $\left(50^{\circ} \mathrm{C}\right)$ to investigate the effect of the seed layer morphology on NW growth.

Figures 2 and 3 show SEM and AFM images of the printed $\mathrm{ZnO}$ seed layers exposed at different annealing times of 0 and $4 \mathrm{~h}$, respectively. The surface morphology changed from close-packed nanoparticulate film (as-printed) up to a dense one (sintered) over time. Indeed, thanks to a dissolution-reprecipitation mechanism during acidic vapor annealing, the chemical bonds among NPs merge particles as per a grain growth phenomenon. From these SEM images, the measured grain size in the non-sintered layers was $45 \pm 12 \mathrm{~nm}$. Concerning the sintered samples, although the evaluation was complex because the grain borders were not well defined, the measured values changed drastically with respect to the non-sintered layers. By the SEM analysis, the grain size ranges from $500 \mathrm{~nm}$ to $1000 \mathrm{~nm}$ with an estimated average of $547 \pm 450 \mathrm{~nm}$.
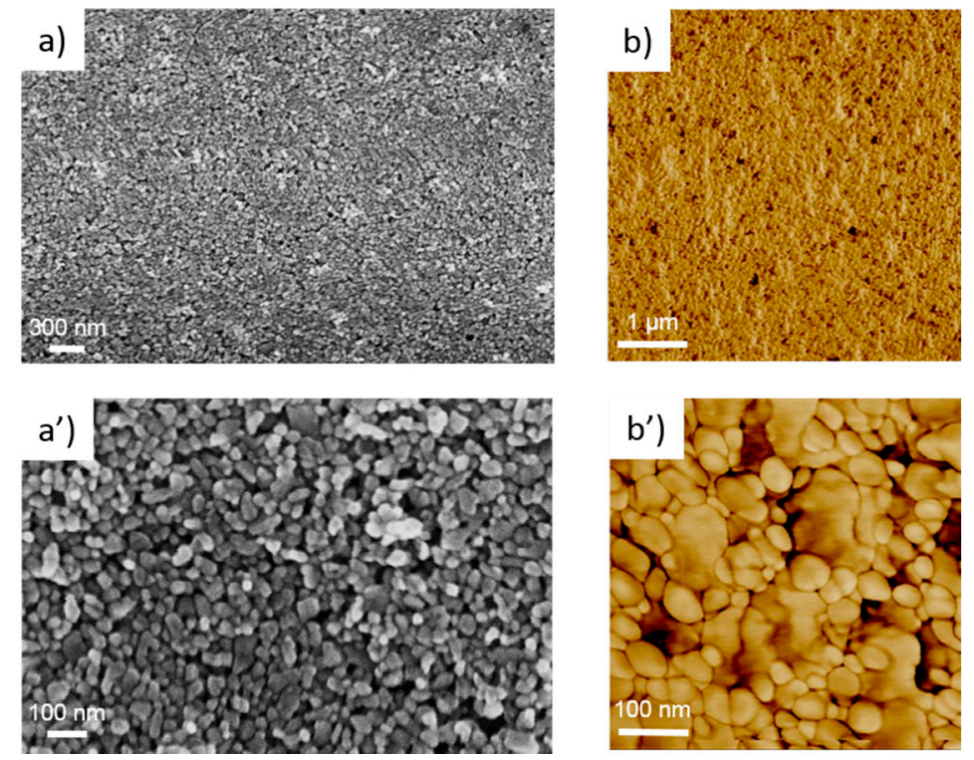

Figure 2. (a) SEM image; (a') magnified SEM image; (b) AFM phase image; $\left(\mathbf{b}^{\prime}\right)$ magnified AFM phase image of the as-printed (non-sintered) $\mathrm{ZnO}$ seed layer. 

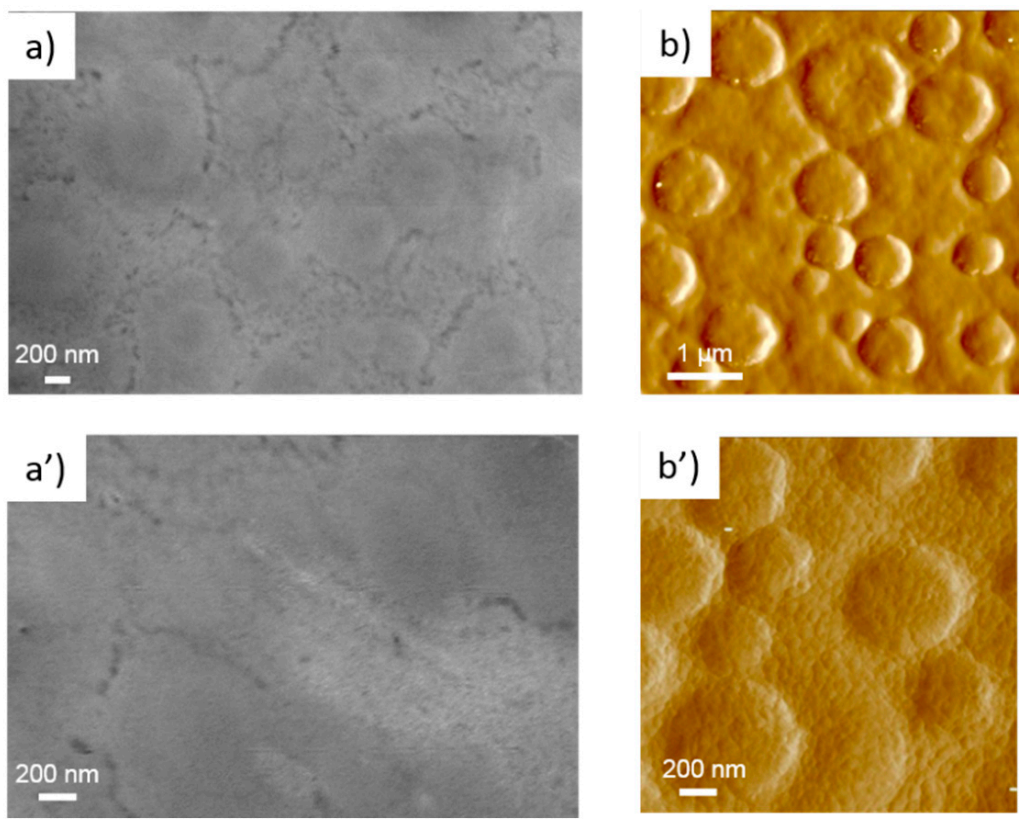

Figure 3. (a) SEM image; (a') magnified SEM image; (b) AFM phase image; (b') magnified AFM phase image of the sintered printed $\mathrm{ZnO}$ seed layer obtained after $4 \mathrm{~h}$ of treatment.

NWs were grown by a CBD method on both types of printed $\mathrm{ZnO}$ seed layers. Moreover, in order to obtain reference samples, NW growth was also performed on a $\mathrm{Si} / \mathrm{ITO} / \mathrm{ZnO}$ substrate where a $\mathrm{ZnO}$ seed layer was deposited by ALD. In Figure $4 \mathrm{a}-\mathrm{c}$, SEM images of the ZnO NWs on the different seed layers are shown. In Figure $4 a^{\prime}-c^{\prime}$, magnified images of the $\mathrm{ZnO} \mathrm{NWs}$ are shown in a similar sequence. The $\mathrm{ZnO}$ NWs that were grown on the $\mathrm{ZnO}$ (ALD)/ITO/Si and the as-printed (not sintered) $\mathrm{ZnO}$ seed layer/ITO/PET substrates have average diameters of nearly $199 \mathrm{~nm}$ and $210 \mathrm{~nm}$ and standard deviations of nearly $86 \mathrm{~nm}$ and $84 \mathrm{~nm}$, respectively. Histograms of these measurements are shown in Figure S5a,b. The ZnO NWs were closely packed and showed good vertical alignment. The obtained $\mathrm{ZnO}$ NWs had relatively small diameters and good alignment, which is important in piezoelectric applications [21], in particular when taking into account the following: (i) low temperature techniques of seed layer deposition; (ii) deposition on flexible substrates; and (iii) the use of non-expensive chemical methods without the requirement of a vacuum (see Table S2). In Figure 4c, it may be observed that the $\mathrm{ZnO} N W s$ were sparsely packed and featured random growth orientations. There was a drastic change in the dimensions of the $\mathrm{ZnO} N W s$, with an average diameter of $987 \mathrm{~nm}$ and standard deviation of $250 \mathrm{~nm}$ (see Figure S5c). Figure S6a,b shows cross-sectional SEM images of $\mathrm{ZnO} N W s$ grown on the ITO/Si and ITO/PET substrates, respectively. It was estimated that the $\mathrm{ZnO}$ NWs were nearly $3.5 \mu \mathrm{m}$ in length. It can be observed that during the growth process of $\mathrm{ZnO} N W s$, some of the NWs merged. The screw-like tops of the $\mathrm{ZnO} N W s$ in Figure $4 \mathrm{c}$ indicates that their growth followed a screw dislocation nucleation mechanism along the axial direction [65]. 

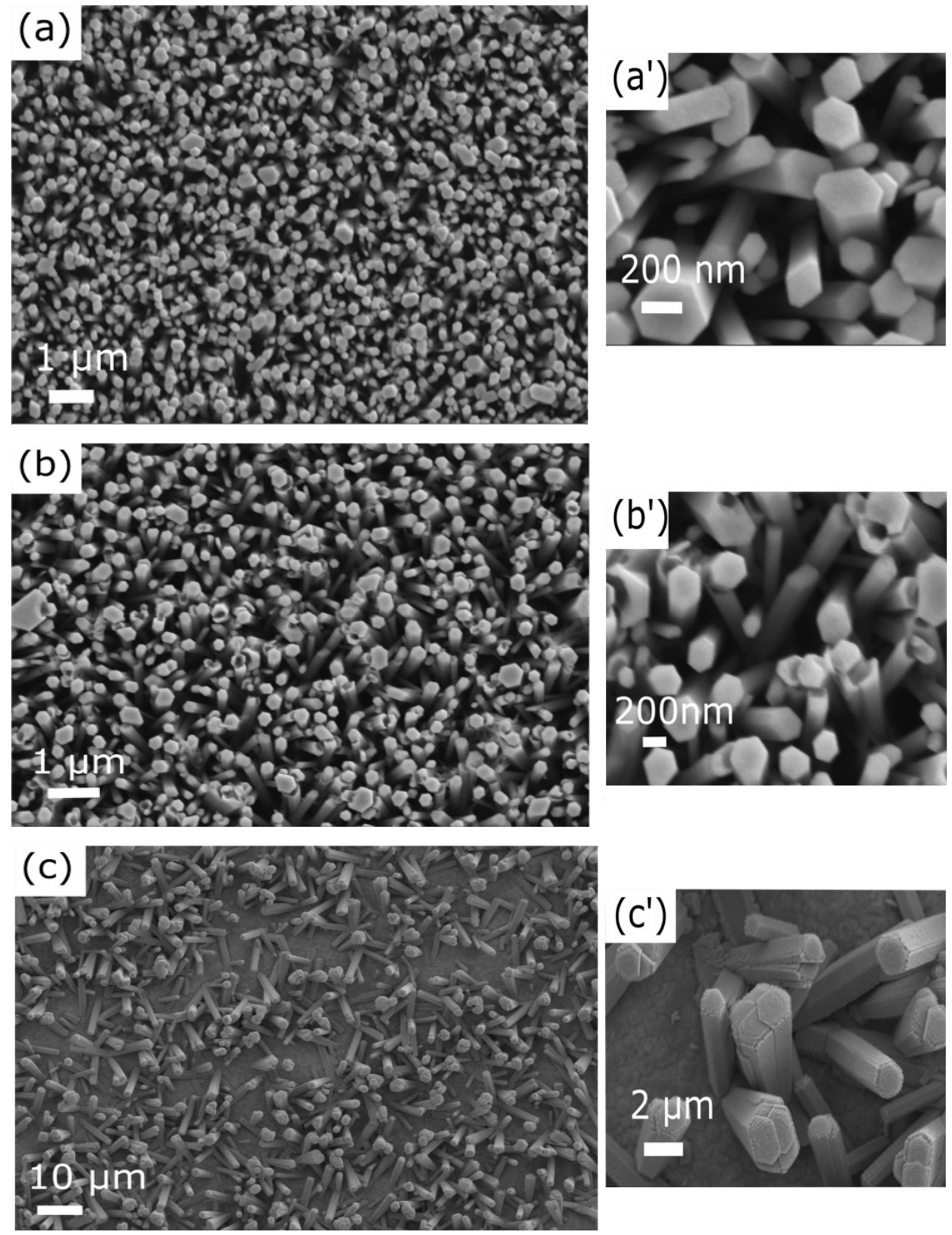

Figure 4. SEM images of the ZnO NWs grown on a (a) ZnO (ALD)/ITO/Si substrate; (a') magnified image; (b) as-printed (non-sintered) ZnO seed layer/ITO/PET; ( $\mathbf{b}^{\prime}$ ) magnified image; (c) sintered printed ZnO seed layer/ITO/PET; (c') magnified image.

As can be seen, the growth of NWs appeared to be significantly affected by the morphology of the seed layer, as also stated in the literature [66-68]; however, the relationships between the seed layer characteristics and NW growth have not been clearly established as of yet. In particular, the seed layer thickness, orientation, and grain size have key roles on the vertical growth of $\mathrm{ZnO}$ NWs. As known, $\mathrm{ZnO}$ preferentially crystallizes in a hexagonal polar wurtzite structure [69]. The $\mathrm{ZnO}$ NW growth direction by CBD occurs predominantly along the polar direction of the seed layer, which provides nucleation sites $[66,67]$.

A possible explanation for the observed results may be proposed on a thermodynamic basis, considering the processes driven by the minimization of the overall system energy. In particular, the seed layer energy governs the nucleation process and subsequently determines the density of $\mathrm{ZnO}$ NWs. 
In general, the energy of a particle is a function of the size, shape, stress, and external environment [70]. In a NP, a significant number of atoms are localized at the surface [69]. The additional energetic term due to the high-energy under-coordinated atoms at the surface is described as the surface free energy [71,72] and becomes increasingly larger as particle size decreases. In addition, several surface defects $[70,73,74]$ may be present, especially when the particle size is very small [75], resulting in a further increase in the particle free energy [76]. As such, due to their high energy, NPs typically show a higher reactivity compared to bulk or micrometric particles [77,78]. As a result, a highly energetic as-printed nanoparticulate seed layer can be especially chemically reactive for $\mathrm{ZnO} \mathrm{NW}$ nucleation. In addition, a NP seed alignment mechanism may be present during the CBD, furthering contributing to the high NW density. As shown in Figure 2, the as-printed seed layer was composed of near-spherical NPs having a wurtzite structure, as demonstrated by Raman spectroscopy (see Figure S7 and Table S3). As with most thin polycrystalline films, nanoparticulate printed layers are not textured [66,79], namely, a random nanocrystal orientation is expected. In fact, in the gravure process, there is no particular force that is able to induce a preferential nanoparticle alignment. The final NP arrangement is determined by the strongly attractive lateral capillary forces among particles during solvent evaporation $[60,80]$. On the other hand, the surface energy distribution of wurtzite-type $\mathrm{ZnO}$ NPs is anisotropic and varies between crystallographic orientations $[69,81]$. Since the NPs are roughly spherical, a large variety of crystallographic planes are presumably exposed to the CBD process [82]. Among these, polar surfaces are extremely chemically reactive $[83,84]$ and have been found to be dominant surface nucleation sites for the growth of $\mathrm{ZnO}$ NWs in a solution [66]. To this regard, it has been observed that a high seed layer texture along the polar axis is necessary to obtain a high NW density $[67,85,86]$. Furthermore, high-density and well-orientated NWs (see Figure $4 b$ ) may support a heattriggered reorientation mechanism for random NPs during the early stages of the CBD [87]. This is possible as the NPs are stuck together by weak physical forces, where they can consequently easily rotate due to the strong electrostatic interactions between charged species (ions, particles, and embryonic dipoles) in the chemical bath, thus reducing the high-energy polar surfaces of wurtzite by nucleation. For these reasons, the as-printed nanoparticulate seed layer demonstrated here can offer a very high number of high-energy nucleation sites (potentially each seed can become a NW, unless steric hindrance interferes). This factor is responsible for the high NW density along the polar c-axis of the hexagonal wurzite crystal (see Figure $4 \mathrm{~b}$ ). Moreover, due to the small sizes of the seeds, the NW diameters were very small, which is typically a challenging result to achieve with most wet chemical methods [88]. Qualitatively, from the SEM images (Figure 4a,b), the NWs grown on the as-printed (non-sintered) layer are comparable in terms of diameter and verticality to the ones grown on the ALD deposited layers.

On the contrary, in the case of a sintered printed sample, far more nucleation sites at lower energy are exposed to the CBD process, resulting in a poor final NW density (see Figure 4c). In fact, sintering is an interface elimination process that decreases the surface area, this creating bonds between contacting particles [89,90]. The total free energy of the system is reduced by replacing the high thermodynamic chemical potential of convex free surfaces of the NPs into lower energy grain boundaries through NP merging. Furthermore, during the densification, the grain boundaries migrate for further reduction of the total free energy, thus resulting in a grain growth phenomenon [91]. Since the grain boundary energy is anisotropic, a lower energy grain boundary tends to extend the most [91-94]. As such, the surfaces of the sintered seeds are mainly dominated by electrically neutral planes [95], which are sites that are not suitable for NW nucleation. Furthermore, the grown grains become trapped by the chemical bonds between grain boundaries. As a result, only some grains with a polar surface available for growth can support nanowires. Such results appear consistent with the observations regarding the decrease in NW density as the seed layer grain size increases [96]. Nevertheless, a chemical sintering post-treatment could be 
investigated in future to induce potential bonding among seeds and between the seeds and substrate, as well as for tuning the nanowire characteristics.

In some recently published articles, it can be found that surfactants like trisodium citrate, ethylenediamine, poly(ethylene glycol), cetyltrimethylammonium bromide, and sodium dodecyl sulphate are used as surfactants, whose role is to change the surface free energy of the different $\mathrm{ZnO}$ crystal facets [97,98]; however, in this work, the role played by the surfactants was complemented by the presence of the seed layer on the substrate.

It is also necessary to discuss the role played by the HMTA in the formation of the $\mathrm{ZnO}$ NWs via a CBD process. Although the exact role of HMTA is still under debate, it is believed that the reagent plays multiple roles in the formation of $\mathrm{ZnO}$ nanocrystals. HMTA is hydrolyzed upon heating into formaldehyde and ammonia. The latter is further protonated in water to produce $\mathrm{OH}^{-}$ions, thus increasing the solution $\mathrm{pH}$. It was found that the rate of decomposition of HMTA is dependent on the concentration of protons in the solution and is independent to the precipitation of $\mathrm{ZnO}[99,100]$. Consequently, it was argued that HMTA fulfills the role of a pH buffer since the rate of hydrolysis is decreases with an increased $\mathrm{pH}$ [101].

In more recent works, it has been shown that the crystal morphology is also strongly influenced by the chemical precursor concentration. A better crystal stoichiometry data have been obtained in the films deposited with larger amounts of HMTA in solution, thus reducing the number of oxygen vacancies and interstitial zinc in the lattice [102].

Additionally, it is believed that HMTA inhibits the growth of nonpolar m-plane sidewalls, thus favoring an anisotropic growth along the c-axis [103].

\section{Piezoelectric Characterization}

To explore the effectiveness of the gravure printing method compared to the ALD process for growing $\mathrm{ZnO}$ seed layers on the flexible substrates, we carried out PFM measurements on the $\mathrm{ZnO}$ (ALD)/ITO/Si and as-printed (not sintered) $\mathrm{ZnO}$ seed layer/ITO/PET samples. The PFM is a widely used tool to study the polarity and the piezo-response properties of piezoelectric thin films and NWs. In this work, the PFM was carried out using the DataCube mode to study the polarities on the top surface of $\mathrm{ZnO}$ NWs by recording the phase signals. The $d_{33}$ piezoelectric coefficients were computed by analysing the piezoelectric amplitudes as presented in Figure $5 \mathrm{a}-\mathrm{f}$.

Figure $5 \mathrm{a}$,b show the topography in an area of $2 \times 2 \mu \mathrm{m}^{2}$ in a top-view of $\mathrm{ZnO} N W \mathrm{~s}$ grown on ITO/Si and ITO/PET structures. At first view, we can see good uniformity and an excellent hexagonal shape for the $\mathrm{ZnO}$ NWs as per the SEM results (Figure 4). Besides, they have the same correlation regarding their diameter (between 53 and $210 \mathrm{~nm}$ ) and roughness parameters at the top end of $\mathrm{ZnO}$ (e.g., root mean square (Rq) values are approximately $120 \mathrm{~nm}$ ). Figure $5 \mathrm{c}$,d show the PFM amplitudes for both samples when an AC drive voltage of $5 \mathrm{~V}$ was applied. The mean amplitude values $(\mu)$ were very similar (22.74 $\pm 8.49 \mathrm{pm}$ and $20.96 \pm 7.21 \mathrm{pm}$, as shown in Figure 6, for ITO/Si and ITO/PET, respectively) according to the Gaussian fitting function for piezoelectric amplitude distribution at the top surface of $\mathrm{ZnO} N W s$. Based on these results, we estimated the effective piezoelectric coefficients $\left(d_{33}^{\text {eff }}\right)$ to be 4.6 and $4.1 \mathrm{pm} / \mathrm{V}$ for the $\mathrm{ZnO} \mathrm{NWs}$ grown on ITO/Si and ITO/PET, respectively. It is important to highlight that both samples presented almost the same $d_{33}^{\text {eff }}$ values and they were inside the range of the previously reported experimental results of 2-12 pm/V [104-108]. 


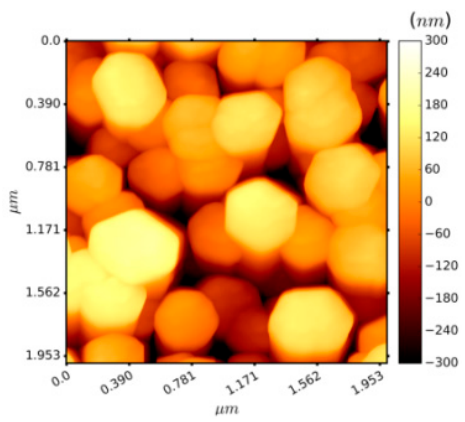

(a)

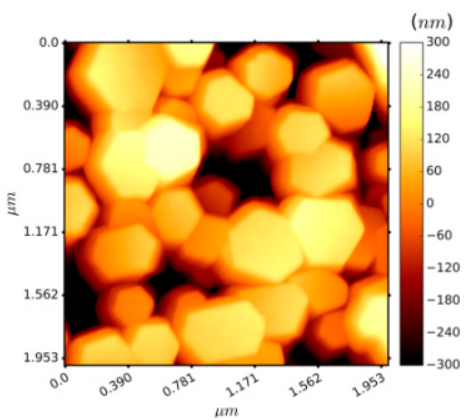

(d)

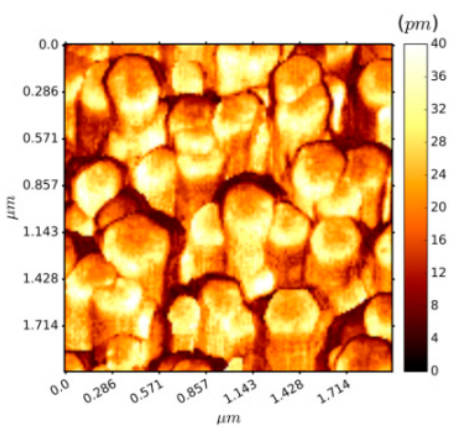

(b)

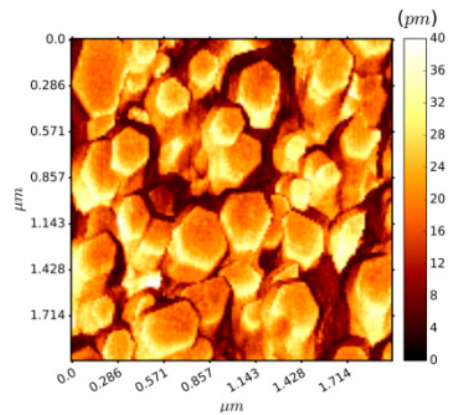

(e)

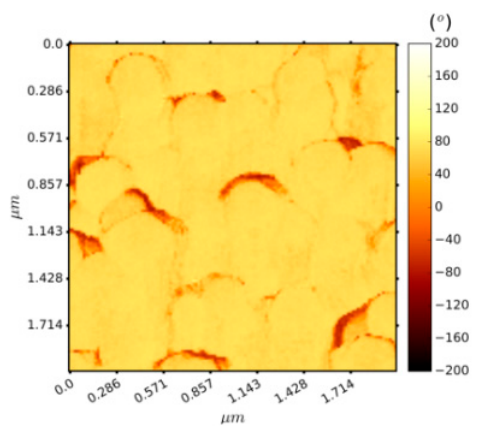

(c)

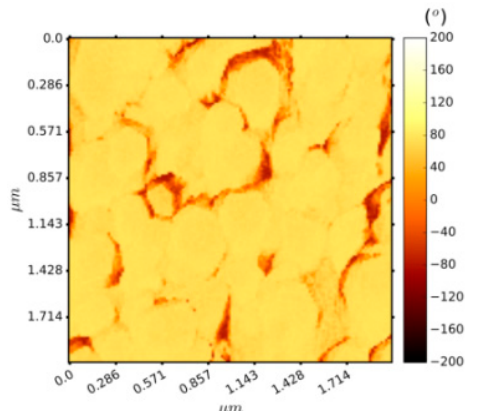

(f)

Figure 5. PFM images of the (a,b) topography, $(\mathbf{c}, \mathbf{d})$ amplitude, and $(\mathbf{e}, \mathbf{f})$ phase of the ZnO NW growth on ZnO (ALD)/ITO/Si (images lined up above) and as-printed (not sintered) ZnO seed layer/ITO/PET substrates (images lined up below).

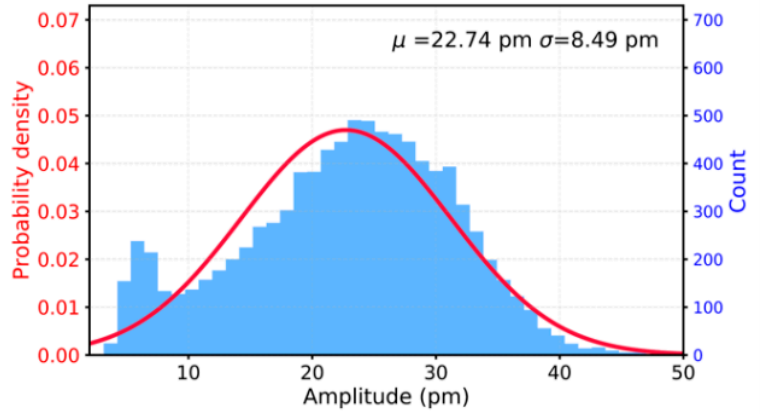

(a)

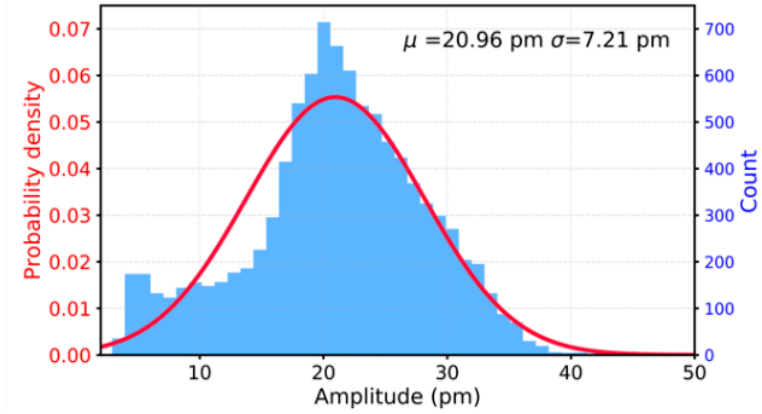

(b)

Figure 6. Piezoelectric amplitude histograms of $\mathrm{ZnO}$ NW growth on (a) $\mathrm{ZnO}$ (ALD)/ITO/Si and (b) as-printed (not sintered) $\mathrm{ZnO}$ seed layer/ITO/PET substrates. The red curve is the Gaussian fitting function.

On the other hand, the PFM measurements also provided results concerning the piezoelectric phase as depicted in Figure 5e,f. Both results show a single-phase value of around $75^{\circ}$ (see Figure S3) throughout the top surface of $\mathrm{ZnO} N W s$, thus demonstrating the $\mathrm{Zn}$ surface polarity of the crystal structure [64]. Obtaining a homogeneous surface polarity is very important at a device level, i.e., where NWs are typically integrated and placed between electrodes [33]. If the NWs had shown negative and positive phase values in their top surface, the induced negative and positive electrical charges would have cancelled out, thus reducing the overall piezoelectric response at the device level.

\section{Conclusions}

In summary, our experimental results show that gravure printing is a promising low-temperature $\mathrm{ZnO}$ seeding method, especially from the perspective of fabricating flexible piezoelectric devices. Study of the printed seed layer morphology revealed that the 
nanoparticulate allowed a better growth of vertical $\mathrm{ZnO}$ NWs by CBD with respect to the sintered one because the high-energy NPs provided a higher number of nucleation sites. To explain the observed results, a possible reorientation mechanism of the $\mathrm{ZnO}$ nanoparticle seeds was also proposed. PFM measurements of the NWs revealed (i) a Zn-phase polarity with a very good homogeneity, which is essential to obtaining globally optimal piezoelectric performance when integrated in devices, and (ii) an estimated piezoelectric coefficient close to $4 \mathrm{pm} / \mathrm{V}$, which is comparable to the NWs grown on Si/ITO substrate.

The mobility and flexibility of the whole structure, provided by the use of flexible $\mathrm{ZnO} \mathrm{NWs}$, is expected to have a good impact on the device's mechanical performance and durability.

This work shows the way towards the fabrication of flexible piezoelectric transducers based on $\mathrm{ZnO}$ nanowires. Fabrication is completely carried out by solution processes at a low temperature.

Supplementary Materials: The following are available online at https:/ / www.mdpi.com/article / 10.3390/nano11061430/s1, Figure S1: sweep of drive frequency value of AC bias signal for PFM amplitude and phase values in different ranges of frequency; Figure S2: single frame of (a) amplitude and (b) phase measurement and average value of 20 frames of (c) amplitude and (d) phase; Figure S3: piezoelectric phase distribution value of ZnO NWs grown on (a) ZnO (ALD)/ITO/Si and (b) asprinted (non-sintered) $\mathrm{ZnO}$ seed layer/ITO/PET substrates. The red curve is the fitting curve using Gaussian mixture models, Figure S4: height distribution of the top surface of (a) ITO over PET, (b) ITO over $\mathrm{Si}$, and (c) ZnO seed layer (deposited by ALD) over ITO/Si to extract the roughness parameters by AFM; Figure S5: diameter distribution of ZnO NWs grown on (a) ZnO (ALD)/ITO/Si and (b) as-printed (non-sintered) $\mathrm{ZnO}$ seed layer/ITO/PET substrates. The red curve is the Gaussian fitting function; Figure S6: SEM image of the cross-section of the ZnO NWs grown on (a) ITO/Si substrate and (b) ITO/PET substrate; Figure S7: Raman spectra of ZnO seed layer films deposited onto aluminium by gravure printing measured before and after $4 \mathrm{~h}$ of sintering; Table S1: arithmetical mean deviation values $(\mathrm{Ra})$ and root squared values $(\mathrm{Rq})$ measured for the different substrates and manufactured $\mathrm{ZnO}$ seed layers; Table S2: comparison table of $\mathrm{ZnO}$ NWs grown by chemical bath deposition (CBD) from recent articles; Table S3: assignments for the Raman bands marked in Figure $\mathrm{S} 2$ to specific vibrations for $\mathrm{ZnO}$ structures.

Author Contributions: Conceptualization, G.A.; G.N.; G.S.; methodology, A.J.L.G.; V.D.; G.S.; M.M.; software, A.J.L.G.; validation, A.J.L.G.; V.D.; G.A.; G.S.; M.M.; formal analysis, A.J.L.G.; investigation, A.J.L.G.; V.D.; M.P.; G.S.; M.M.; F.L.; F.V.; resources, X.M.; G.S.; M.M.; F.L.; F.V.; data curation, A.J.L.G.; writing—original draft preparation, A.J.L.G.; G.A.; V.D.; M.P.; G.S.; M.M.; F.L.; F.V.; G.N.; writing-review and editing, G.A.; M.P.; X.M.; G.S.; M.M.; F.L.; F.V.; G.N.; visualization, A.J.L.G.; V.D.; supervision, G.A.; project administration, G.A.; funding acquisition, G.A.; G.N. All authors have read and agreed to the published version of the manuscript.

Funding: This work has received funding from project PULSE-COM of the European Union's Horizon 2020 research and innovation program under grant agreement No. 863227.

Data Availability Statement: The data are available upon request from the corresponding authors.

Acknowledgments: This work has been performed with the help of the "Plateforme Technologique Amont" from Grenoble.

Conflicts of Interest: The authors declare no conflict of interest.

\section{References}

1. Aliqué, M.; Simão, C.D.; Murillo, G.; Moya, A. Fully-Printed Piezoelectric Devices for Flexible Electronics Applications. Adv. Mater. Technol. 2021, 6, 2001020. [CrossRef]

2. Martins, P.; Lopes, A.C.; Lanceros-Mendez, S. Electroactive phases of poly(vinylidene fluoride): Determination, processing and applications. Prog. Polym. Sci. 2014, 39, 683-706. [CrossRef]

3. Bhavanasi, V.; Kumar, V.; Parida, K.; Wang, J.; Lee, P.S. Enhanced Piezoelectric Energy Harvesting Performance of Flexible PVDF-TrFE Bilayer Films with Graphene Oxide. ACS Appl. Mater. Interfaces 2016, 8, 521-529. [CrossRef]

4. Wu, Y.; Qu, J.; Daoud, W.A.; Wang, L.; Qi, T. Flexible composite-nanofiber based piezo-triboelectric nanogenerators for wearable electronics. J. Mater. Chem. A 2019, 7, 13347-13355. [CrossRef] 
5. Costa, P.; Nunes-Pereira, J.; Pereira, N.; Castro, N.; Gonçalves, S.; Lanceros-Mendez, S. Recent Progress on Piezoelectric, Pyroelectric, and Magnetoelectric Polymer-Based Energy-Harvesting Devices. Energy Technol. 2019, 7, 1-19. [CrossRef]

6. Gupta, S.; Bhunia, R.; Fatma, B.; Maurya, D.; Singh, D.; Gupta, R.; Priya, S.; Gupta, R.K.; Garg, A. Multifunctional and Flexible Polymeric Nanocomposite Films with Improved Ferroelectric and Piezoelectric Properties for Energy Generation Devices. ACS Appl. Mater. Interfaces 2019, 2, 6364-6374. [CrossRef]

7. Kang, H.B.; Han, C.S.; Pyun, J.C.; Ryu, W.H.; Kang, C.Y.; Cho, Y.S. (Na,K) $\mathrm{NbO}_{3}$ nanoparticle-embedded piezoelectric nanofiber composites for flexible nanogenerators. Compos. Sci. Technol. 2015, 111, 1-8. [CrossRef]

8. Hwang, G.T.; Park, H.; Lee, J.H.; Oh, S.; Park, K.I.; Byun, M.; Park, H.; Ahn, G.; Jeong, C.K.; No, K.; et al. Self-powered cardiac pacemaker enabled by flexible single crystalline PMN-PT piezoelectric energy harvester. Adv. Mater. 2014, 26, 4880-4887. [CrossRef]

9. Dudem, B.; Kim, D.H.; Bharat, L.K.; Yu, J.S. Highly-flexible piezoelectric nanogenerators with silver nanowires and barium titanate embedded composite films for mechanical energy harvesting. Appl. Energy 2018, 230, 865-874. [CrossRef]

10. Rovisco, A.; dos Santos, A.; Cramer, T.; Martins, J.; Branquinho, R.; Águas, H.; Fraboni, B.; Fortunato, E.; Martins, R.; Igreja, R. Piezoelectricity Enhancement of Nanogenerators Based on PDMS and $\mathrm{ZnSnO}_{3}$ Nanowires through Microstructuration. ACS Appl. Mater. Interfaces 2020, 12, 18421-18430. [CrossRef]

11. Queraltó, A.; Frohnhoven, R.; Mathur, S.; Gómez, A. Intrinsic piezoelectric characterization of $\mathrm{BiFeO}_{3}$ nanofibers and its implications for energy harvesting. Appl. Surf. Sci. 2020, 509, 144760-144767. [CrossRef]

12. Yang, D.; Qiu, Y.; Jiang, Q.; Guo, Z.; Song, W.; Xu, J.; Zong, Y.; Feng, Q.; Sun, X. Patterned growth of ZnO nanowires on flexible substrates for enhanced performance of flexible piezoelectric nanogenerators. Appl. Phys. Lett. 2017, 110, 63901-63905. [CrossRef]

13. Panth, M.; Cook, B.; Alamri, M.; Ewing, D.; Wilson, A.; Wu, J.Z. Flexible zinc oxide nanowire array/graphene nanohybrid for high-sensitivity strain detection. ACS Omega 2020, 5, 27359-27367. [CrossRef] [PubMed]

14. Wei, H.; Wang, H.; Xia, Y.; Cui, D.; Shi, Y.; Dong, M.; Liu, C.; Ding, T.; Zhang, J.; Ma, Y. An overview of lead-free piezoelectric materials and devices. J. Mater. Chem. C 2018, 6, 12446-12467. [CrossRef]

15. Hughes, W.L.; Wang, Z.L. Controlled synthesis and manipulation of ZnO nanorings and nanobows. Appl. Phys. Lett. 2005, 86, 43106. [CrossRef]

16. Espinosa, H.D.; Bernal, R.A.; Minary-Jolandan, M. A review of mechanical and electromechanical properties of piezoelectric nanowires. Adv. Mater. 2012, 24, 4656-4675. [CrossRef] [PubMed]

17. Jing, G.; Zhang, X.; Yu, D. Effect of surface morphology on the mechanical properties of ZnO nanowires. Appl. Phys. A 2010, 100, 473-478. [CrossRef]

18. Chen, C.Q.; Shi, Y.; Zhang, Y.S.; Zhu, J.; Yan, Y.J. Size dependence of Young's modulus in ZnO nanowires. Phys. Rev. Lett. 2006, 96, 75505-75508. [CrossRef]

19. Soomro, M.Y.; Hussain, I.; Bano, N.; Broitman, E.; Nur, O.; Willander, M. Nanoscale elastic modulus of single horizontal ZnO nanorod using nanoindentation experiment. Nanoscale Res. Lett. 2012, 7, 1-5. [CrossRef]

20. Agrawal, R.; Espinosa, H.D. Giant piezoelectric size effects in zinc oxide and gallium nitride nanowires. A first principles investigation. Nano Lett. 2011, 11, 786-790. [CrossRef] [PubMed]

21. Tao, R.; Mouis, M.; Ardila, G. Unveiling the influence of surface fermi level pinning on the piezoelectric response of semiconducting nanowires. Adv. Electron. Mater. 2018, 4, 1700299. [CrossRef]

22. Hussain, S.; Liu, T.; Aslam, N.; Kashif, M.; Cao, S.; Rashad, M.; Zhang, Y.; Zeng, W.; Javed, M.S. Polymer-assisted co-axial multi-layered circular ZnO nanodisks. Mater. Lett. 2015, 152, 260-263. [CrossRef]

23. Hussain, S.; Liu, T.; Aslam, N.; Zhao, S.; Li, T.; Hou, D.; Zeng, W. Assembly of bulbous ZnO nanorods to bulbous nanoflowers and their high selectivity towards formaldehyde. J. Mater. Sci. Mater. Electron. 2016, 27, 4966-4971. [CrossRef]

24. Hussain, S.; Yang, X.; Aslam, M.K.; Shaheen, A.; Javed, M.S.; Aslam, N.; Aslam, B.; Liu, G.; Qiao, G. Robust TiN nanoparticles polysulfide anchor for Li-S storage and diffusion pathways using first principle calculations. Chem. Eng. J. 2020, $391,123595$. [CrossRef]

25. Hussain, S.; Khan, A.J.; Arshad, M.; Javed, M.S.; Ahmad, A.; Shah, S.S.A.; Khan, M.R.; Akram, S.; Zulfiqar; Ali, S.; et al. Charge storage in binder-free 2D-hexagonal $\mathrm{CoMoO}_{4}$ nanosheets as a redox active material for pseudocapacitors. Ceram. Int. 2021, 47, 8659-8667. [CrossRef]

26. Hussain, S.; Hassan, M.; Javed, M.S.; Shaheen, A.; Ahmad Shah, S.S.; Nazir, M.T.; Najam, T.; Khan, A.J.; Zhang, X.; Liu, G. Distinctive flower-like $\mathrm{CoNi}_{2} \mathrm{~S}_{4}$ nanoneedle arrays (CNS-NAs) for superior supercapacitor electrode performances. Ceram. Int. 2020, 46, 25942-25948. [CrossRef]

27. Wang, Z.L.; Song, J. Piezoelectric Nanogenerators Based on Zinc Oxide Nanowire. Science 2006, 312, 242-246. [CrossRef] [PubMed]

28. Yang, R.; Qin, Y.; Li, C.; Zhu, G.; Wang, Z.L. Converting biomechanical energy into electricity by a muscle-movement-driven nanogenerator. Nano Lett. 2009, 9, 1201-1205. [CrossRef]

29. Yim, M.; Jeon, B.; Yoon, G. Fabrication of tandem-type vertically integrated nanogenerator by in-situ deposition of AlN/ZnO films. J. Semicond. Technol. Sci. 2019, 19, 233-238. [CrossRef]

30. Dahiya, A.S.; Morini, F.; Boubenia, S.; Nadaud, K.; Alquier, D.; Poulin-Vittrant, G. Organic/Inorganic Hybrid Stretchable Piezoelectric Nanogenerators for Self-Powered Wearable Electronics. Adv. Mater. Technol. 2018, 3, 1-11. [CrossRef] 
31. Lee, S.; Bae, S.H.; Lin, L.; Yang, Y.; Park, C.; Kim, S.W.; Cha, S.N.; Kim, H.; Park, Y.J.; Wang, Z.L. Super-flexible nanogenerator for energy harvesting from gentle wind and as an active deformation sensor. Adv. Funct. Mater. 2013, 23, 2445-2449. [CrossRef]

32. Yu, A.; Li, H.; Tang, H.; Liu, T.; Jiang, P.; Wang, Z.L. Vertically integrated nanogenerator based on ZnO nanowire arrays. Phys. Status Solidi Rapid Res. Lett. 2011, 5, 162-164. [CrossRef]

33. Tao, R.; Parmar, M.; Ardila, G.; Oliveira, P.; Marques, D.; Montès, L.; Mouis, M. Performance of ZnO based piezo-generators under controlled compression. Semicond. Sci. Technol. 2017, 32, 064003. [CrossRef]

34. Hu, Y.; Lin, L.; Zhang, Y.; Wang, Z.L. Replacing a battery by a nanogenerator with 20 v output. Adv. Mater. 2012, $24,110-114$. [CrossRef]

35. Zhu, G.; Wang, A.C.; Liu, Y.; Zhou, Y.; Wang, Z.L. Functional electrical stimulation by nanogenerator with 58 V output voltage. Nano Lett. 2012, 12, 3086-3090. [CrossRef] [PubMed]

36. Yuan, H.; Lei, T.; Qin, Y.; Yang, R. Flexible electronic skins based on piezoelectric nanogenerators and piezotronics. Nano Energy 2019, 59, 84-90. [CrossRef]

37. He, H.; Fu, Y.; Zang, W.; Wang, Q.; Xing, L.; Zhang, Y.; Xue, X. A flexible self-powered T-ZnO/PVDF/fabric electronic-skin with multi-functions of tactile-perception, atmosphere-detection and self-clean. Nano Energy 2017, 31, 37-48. [CrossRef]

38. Baxter, J.B.; Schmuttenmaer, C.A. Conductivity of $\mathrm{ZnO}$ nanowires, nanoparticles, and thin films using time-resolved terahertz spectroscopy. J. Phys. Chem. B 2006, 110, 25229-25239. [CrossRef]

39. Villafuerte, J.; Donatini, F.; Kioseoglou, J.; Sarigiannidou, E.; Chaix-Pluchery, O.; Pernot, J.; Consonni, V. Zinc Vacancy-Hydrogen Complexes as Major Defects in ZnO Nanowires Grown by Chemical Bath Deposition. J. Phys. Chem. C 2020, 124, 16652-16662. [CrossRef]

40. Sugunan, A.; Warad, H.C.; Boman, M.; Dutta, J. Zinc oxide nanowires in chemical bath on seeded substrates: Role of hexamine. J. Sol-Gel Sci. Technol. 2006, 39, 49-56. [CrossRef]

41. Chelu, M.; Stroescu, H.; Anastasescu, M.; Calderon-Moreno, J.M.; Preda, S.; Stoica, M.; Fogarassy, Z.; Petrik, P.; Gheorghe, M.; Parvulescu, C. High-quality PMMA/ZnO NWs piezoelectric coating on rigid and flexible metallic substrates. Appl. Surf. Sci. 2020, 529, 147135-147144. [CrossRef]

42. Yang, W.; Wang, Y.; Hou, Z.; Li, C. A facile hot-pressing process for fabricating flexible top electrodes of piezoelectric ZnO nanowire nanogenerators. Nanotechnology 2019, 30, 505402-505407. [CrossRef] [PubMed]

43. Deng, W.; Jin, L.; Zhang, B.; Chen, Y.; Mao, L.; Zhang, H.; Yang, W. A flexible field-limited ordered ZnO nanorod-based self-powered tactile sensor array for electronic skin. Nanoscale 2016, 8, 16302-16306. [CrossRef] [PubMed]

44. Yilmaz, P.; Greenwood, P.; Meroni, S.; Troughton, J.; Novák, P.; Li, X.; Watson, T.; Briscoe, J. Self-adhesive electrode applied to $\mathrm{ZnO}$ nanorod-based piezoelectric nanogenerators. Smart Mater. Struct. 2019, 28, 105040. [CrossRef]

45. Zhang, Y.; Liu, C.; Liu, J.; Xiong, J.; Liu, J.; Zhang, K.; Liu, Y.; Peng, M.; Yu, A.; Zhang, A. Lattice strain induced remarkable enhancement in piezoelectric performance of ZnO-based flexible nanogenerators. ACS Appl. Mater. Interfaces 2016, 8, 1381-1387. [CrossRef] [PubMed]

46. Wojnarowicz, J.; Chudoba, T.; Lojkowski, W. A Review of Microwave Synthesis of Zinc Oxide Nanomaterials: Reactants, Process Parameters and Morphoslogies. Nanomaterials 2020, 10, 1086. [CrossRef]

47. Noack, V.; Eychmüller, A. Annealing of nanometer-sized zinc oxide particles. Chem. Mater. 2002, 14, 1411-1417. [CrossRef]

48. Mosalagae, K.; Murape, D.M.; Lepodise, L.M. Effects of growth conditions on properties of CBD synthesized ZnO nanorods grown on ultrasonic spray pyrolysis deposited $\mathrm{ZnO}$ seed layers. Heliyon 2020, 6, e04458-e04467. [CrossRef]

49. Chang, S.-Y.; Yang, N.-H.; Huang, Y.-C.; Lin, S.-J.; Kattamis, T.Z.; Liu, C.-Y. Spontaneous growth of one-dimensional nanostructures from films in ambient atmosphere at room temperature: $\mathrm{ZnO}$ and $\mathrm{TiO}_{2}$. J. Mater. Chem. 2011, 21, 4264-4271. [CrossRef]

50. Peiris, T.A.N.; Alessa, H.; Sagu, J.S.; Bhatti, I.A.; Isherwood, P.; Wijayantha, K.G.U. Effect of ZnO seed layer thickness on hierarchical $\mathrm{ZnO}$ nanorod growth on flexible substrates for application in dye-sensitised solar cells. J. Nanoparticle Res. 2013, 15, 2115-2124. [CrossRef]

51. Burke-Govey, C.P.; Plank, N.O.V. Review of hydrothermal ZnO nanowires: Toward FET applications. J. Vac. Sci. Technol. B Nanotechnol. Microelectron. Mater. Process. Meas. Phenom. 2013, 31, F101-F106. [CrossRef]

52. Wei, P.; Zhu, D.; Huang, S.; Zhou, W.; Luo, F. Effects of the annealing temperature and atmosphere on the microstructures and dielectric properties of $\mathrm{ZnO} / \mathrm{Al}_{2} \mathrm{O}_{3}$ composite coatings. Appl. Surf. Sci. 2013, 285, 577-582. [CrossRef]

53. Ranjan, P.; Suematsu, H.; Chakravarthy, S.R.; Jayaganthan, R.; Sarathi, R. Thermodynamic analysis of ZnO nanoparticle formation by wire explosion process and characterization. Ceram. Int. 2017, 43, 6709-6720. [CrossRef]

54. Wu, W. Inorganic nanomaterials for printed electronics: A review. Nanoscale 2017, 9, 7342-7372. [CrossRef]

55. Abbel, R.; Galagan, Y.; Groen, P. Roll-to-Roll Fabrication of Solution Processed Electronics. Adv. Eng. Mater. 2018, 20, 1701190-1701219. [CrossRef]

56. Khan, S.; Lorenzelli, L.; Dahiya, R.S. Technologies for printing sensors and electronics over large flexible substrates: A review. IEEE Sens. J. 2014, 15, 3164-3185. [CrossRef]

57. Arrabito, G.; Aleeva, Y.; Pezzilli, R.; Ferrara, V.; Medaglia, P.G.; Pignataro, B.; Prestopino, G. Printing ZnO Inks: From Principles to Devices. Crystals 2020, 10, 449. [CrossRef]

58. Søndergaard, R.R.; Hösel, M.; Krebs, F.C. Roll-to-Roll fabrication of large area functional organic materials. J. Polym. Sci. Part. B Polym. Phys. 2013, 51, 16-34. [CrossRef] 
59. Krebs, F.C. Fabrication and processing of polymer solar cells: A review of printing and coating techniques. Sol. Energy Mater. Sol. Cells 2009, 93, 394-412. [CrossRef]

60. Sico, G.; Montanino, M.; Prontera, C.T.; Del Mauro, A.D.G.; Minarini, C. Gravure printing for thin film ceramics manufacturing from nanoparticles. Ceram. Int. 2018, 44, 19526-19534. [CrossRef]

61. Sico, G.; Montanino, M.; Ventre, M.; Mollo, V.; Prontera, C.T.; Minarini, C.; Magnani, G. Pressureless sintering of ZnO thin film on plastic substrate via vapor annealing process at near-room temperature. Scr. Mater. 2019, 164, 48-51. [CrossRef]

62. Choi, Y.; Kim, G.H.; Jeong, W.H.; Kim, H.J.; Chin, B.D.; Yu, J.-W. Characteristics of gravure printed InGaZnO thin films as an active channel layer in thin film transistors. Thin Solid Film. 2010, 518, 6249-6252. [CrossRef]

63. Kim, S.; Seol, D.; Lu, X.; Alexe, M.; Kim, Y. Electrostatic-free piezoresponse force microscopy. Sci. Rep. 2017, 7, 1-8. [CrossRef] [PubMed]

64. Bui, Q.C.; Ardila, G.; Sarigiannidou, E.; Roussel, H.; Jiménez, C.; Chaix-Pluchery, O.; Guerfi, Y.; Bassani, F.; Donatini, F.; Mescot, X.; et al. Morphology Transition of ZnO from Thin Film to Nanowires on Silicon and its Correlated Enhanced Zinc Polarity Uniformity and Piezoelectric Responses. ACS Appl. Mater. Interfaces 2020, 12, 29583-29593. [CrossRef]

65. Kumar, Y.; Rana, A.K.; Bhojane, P.; Pusty, M.; Bagwe, V.; Sen, S.; Shirage, P.M. Controlling of ZnO nanostructures by solute concentration and its effect on growth, structural and optical properties. Mater. Res. Express 2015, 2, 105017-105027. [CrossRef]

66. Guillemin, S.; Consonni, V.; Appert, E.; Puyoo, E.; Rapenne, L.; Roussel, H. Critical nucleation effects on the structural relationship between ZnO seed layer and nanowires. J. Phys. Chem. C 2012, 116, 25106-25111. [CrossRef]

67. Guillemin, S.; Rapenne, L.; Roussel, H.; Sarigiannidou, E.; Brémond, G.; Consonni, V. Formation mechanisms of ZnO nanowires: The crucial role of crystal orientation and polarity. J. Phys. Chem. C 2013, 117, 20738-20745. [CrossRef]

68. Abdulrahman, A.F.; Ahmed, S.M.; Ahmed, N.M.; Almessiere, M.A. Enhancement of ZnO Nanorods Properties Using Modified Chemical Bath Deposition Method: Effect of Precursor Concentration. Crystals 2020, 10, 386. [CrossRef]

69. Zuniga-Perez, J.; Consonni, V.; Lymperakis, L.; Kong, X.; Trampert, A.; Fernandez-Garrido, S.; Brandt, O.; Renevier, H.; Keller, S.; Hestroffer, K. Polarity in GaN and ZnO: Theory, measurement, growth, and devices. Appl. Phys. Rev. 2016, 3, 41303-41402. [CrossRef]

70. Marks, L.D.; Peng, L. Nanoparticle shape, thermodynamics and kinetics. J. Phys. Condens. Matter 2016, 28, 53001-53048. [CrossRef]

71. Levitas, V.I.; Samani, K. Size and mechanics effects in surface-induced melting of nanoparticles. Nat. Commun. 2011, 2, 1-6. [CrossRef]

72. Vollath, D.; Fischer, F.D.; Holec, D. Surface energy of nanoparticles-influence of particle size and structure. Beilstein J. Nanotechnol. 2018, 9, 2265-2276. [CrossRef]

73. Biener, J.; Wittstock, A.; Baumann, T.F.; Weissmüller, J.; Bäumer, M.; Hamza, A.V. Surface chemistry in nanoscale materials. Materials 2009, 2, 2404-2428. [CrossRef]

74. Choudhary, K.; Biacchi, A.J.; Ghosh, S.; Hale, L.; Walker, A.R.H.; Tavazza, F. High-throughput assessment of vacancy formation and surface energies of materials using classical force-fields. J. Phys. Condens. Matter 2018, 30, 395901. [CrossRef] [PubMed]

75. Meulenkamp, E.A. Synthesis and growth of ZnO nanoparticles. J. Phys. Chem. B 1998, 102, 5566-5572. [CrossRef]

76. Przybyszewska, M.; Krzywania, A.; Zaborski, M.; Szynkowska, M.I. Surface properties of zinc oxide nanoparticles studied by inverse gas chromatography. J. Chromatogr. A 2009, 1216, 5284-5291. [CrossRef] [PubMed]

77. Lu, H.M.; Jiang, Q. Size-dependent surface energies of nanocrystals. J. Phys. Chem. B 2004, 108, 5617-5619. [CrossRef]

78. He, H.; Cao, J.; Duan, N. Defects and their behaviors in mineral dissolution under water environment: A review. Sci. Total Environ. 2019, 651, 2208-2217. [CrossRef] [PubMed]

79. Ching, K.-L.; Li, G.; Ho, Y.-L.; Kwok, H.-S. The role of polarity and surface energy in the growth mechanism of ZnO from nanorods to nanotubes. CrystEngComm 2016, 18, 779-786. [CrossRef]

80. Kralchevsky, P.A.; Nagayama, K. Capillary forces between colloidal particles. Langmuir 1994, 10, 23-36. [CrossRef]

81. Mudunkotuwa, I.A.; Grassian, V.H. The devil is in the details (or the surface): Impact of surface structure and surface energetics on understanding the behavior of nanomaterials in the environment. J. Environ. Monit. 2011, 13, 1135-1144. [CrossRef] [PubMed]

82. Zhang, P.; Xu, F.; Navrotsky, A.; Lee, J.S.; Kim, S.; Liu, J. Surface enthalpies of nanophase ZnO with different morphologies. Chem. Mater. 2007, 19, 5687-5693. [CrossRef]

83. Tang, C.; Spencer, M.J.S.; Barnard, A.S. Activity of ZnO polar surfaces: An insight from surface energies. Phys. Chem. Chem. Phys. 2014, 16, 22139-22144. [CrossRef] [PubMed]

84. Connolly, B.M.; Greer, H.F.; Zhou, W. Formation Mechanisms of ZnO Spherulites and Derivatives. Cryst. Growth Des. 2018, 19, 249-257. [CrossRef]

85. Demes, T.; Ternon, C.; Riassetto, D.; Stambouli, V.; Langlet, M. Comprehensive study of hydrothermally grown ZnO nanowires. J. Mater. Sci. 2016, 51, 10652-10661. [CrossRef]

86. Cossuet, T.; Roussel, H.; Chauveau, J.-M.; Chaix-Pluchery, O.; Thomassin, J.-L.; Appert, E.; Consonni, V. Well-ordered ZnO nanowires with controllable inclination on semipolar ZnO surfaces by chemical bath deposition. Nanotechnology 2018, 29, 475601-475612. [CrossRef] [PubMed]

87. Theissmann, R.; Fendrich, M.; Zinetullin, R.; Guenther, G.; Schierning, G.; Wolf, D.E. Crystallographic reorientation and nanoparticle coalescence. Phys. Rev. B 2008, 78, 205413-205421. [CrossRef]

88. Ali, A.; Ambreen, S.; Javed, R.; Tabassum, S.; Ul Haq, I.; Zia, M. ZnO nanostructure fabrication in different solvents transforms physio-chemical, biological and photodegradable properties. Mater. Sci. Eng. C 2017, 74, 137-145. [CrossRef] 
89. Castro, R.H.R.; Gouvêa, D. Sintering and nanostability: The thermodynamic perspective. J. Am. Ceram. Soc. 2016, 99, 1105-1121. [CrossRef]

90. German, R.M. Sintering trajectories: Description on how density, surface area, and grain size change. JOM 2016, 68, 878-884. [CrossRef]

91. Rohrer, G.S. Grain boundary energy anisotropy: A review. J. Mater. Sci. 2011, 46, 5881-5895. [CrossRef]

92. Lee, J.; Wiederhorn, S.M. Effects of polarity on grain-boundary migration in ZnO. J. Am. Ceram. Soc. 2004, 87, 1319-1323. [CrossRef]

93. German, R.M. Coarsening in sintering: Grain shape distribution, grain size distribution, and grain growth kinetics in solid-pore systems. Crit. Rev. Solid State Mater. Sci. 2010, 35, 263-305. [CrossRef]

94. Sui, M.; Pandey, P.; Li, M.-Y.; Zhang, Q.; Kunwar, S.; Lee, J. Tuning the configuration of Au nanostructures: From vermiform-like, rod-like, triangular, hexagonal, to polyhedral nanostructures on c-plane GaN. J. Mater. Sci. 2017, 52, 391-407. [CrossRef]

95. Kuang, Q.; Wang, X.; Jiang, Z.; Xie, Z.; Zheng, L. High-energy-surface engineered metal oxide micro- and nanocrystallites and their applications. Acc. Chem. Res. 2014, 47, 308-318. [CrossRef]

96. Syrrokostas, G.; Govatsi, K.; Yannopoulos, S.N. High-Quality, Reproducible ZnO Nanowire Arrays Obtained by a Multiparameter Optimization of Chemical Bath Deposition Growth. Cryst. Growth Des. 2016, 16, 2140-2150. [CrossRef]

97. Hussain, S.; Liu, T.; Kashif, M.; Miao, B.; He, J.; Zeng, W.; Zhang, Y.; Hashim, U.; Pan, F. Surfactant dependent growth of twinned ZnO nanodisks. Mater. Lett. 2014, 118, 165-168. [CrossRef]

98. Qiu, J.; Weng, B.; Zhao, L.; Chang, C.; Shi, Z.; Li, X.; Kim, H.K.; Hwang, Y.H. Synthesis and characterization of flower-like bundles of $\mathrm{ZnO}$ nanosheets by a surfactant-free hydrothermal process. J. Nanomater. 2014, 2014. [CrossRef]

99. Ashfold, M.N.R.; Doherty, R.P.; Ndifor-Angwafor, N.G.; Riley, D.J.; Sun, Y. The kinetics of the hydrothermal growth of ZnO nanostructures. Thin Solid Film. 2007, 515, 8679-8683. [CrossRef]

100. Strom, J.G., Jr.; Jun, H.W. Kinetics of hydrolysis of methenamine. J. Pharm. Sci. 1980, 69, 1261-1263. [CrossRef] [PubMed]

101. Govender, K.; Boyle, D.S.; Kenway, P.B.; O’Brien, P. Understanding the factors that govern the deposition and morphology of thin films of $\mathrm{ZnO}$ from aqueous solution. J. Mater. Chem. 2004, 14, 2575-2591. [CrossRef]

102. Ruiz-Rojas, C.A.; Aguilar-Frutis, M.; Ramos-Brito, F.; Garduno-Wilches, I.A.; Narro-Ríos, J.; Lartundo-Rojas, L.; Alarcón-Flores, G. Synthesis, characterization, and temperature-dependent electronic properties of ZnO nanorods using CBD techniques. J. Mater. Sci. Mater. Electron. 2021, 1-14. [CrossRef]

103. Parize, R.; Garnier, J.; Chaix-Pluchery, O.; Verrier, C.; Appert, E.; Consonni, V. Effects of Hexamethylenetetramine on the Nucleation and Radial Growth of ZnO Nanowires by Chemical Bath Deposition. J. Phys. Chem. C 2016, 120, 5242-5250. [CrossRef]

104. Tamvakos, D.; Lepadatu, S.; Antohe, V.-A.; Tamvakos, A.; Weaver, P.M.; Piraux, L.; Cain, M.G.; Pullini, D. Piezoelectric properties of template-free electrochemically grown ZnO nanorod arrays. Appl. Surf. Sci. 2015, 356, 1214-1220. [CrossRef]

105. Broitman, E.; Soomro, M.Y.; Lu, J.; Willander, M.; Hultman, L. Nanoscale piezoelectric response of ZnO nanowires measured using a nanoindentation technique. Phys. Chem. Chem. Phys. 2013, 15, 11113-11118. [CrossRef] [PubMed]

106. Fan, H.J.; Lee, W.; Hauschild, R.; Alexe, M.; Le Rhun, G.; Scholz, R.; Dadgar, A.; Nielsch, K.; Kalt, H.; Krost, A. Template-assisted large-scale ordered arrays of $\mathrm{ZnO}$ pillars for optical and piezoelectric applications. Small 2006, 2, 561-568. [CrossRef] [PubMed]

107. Scrymgeour, D.A.; Sounart, T.L.; Simmons, N.C.; Hsu, J.W.P. Polarity and piezoelectric response of solution grown zinc oxide nanocrystals on silver. J. Appl. Phys. 2007, 101, 14316-14321. [CrossRef]

108. Cavallini, D.; Fortunato, M.; De Bellis, G.; Sarto, M.S. PFM Characterization of Piezoelectric PVDF/ZnONanorod thin films. In Proceedings of the 2018 IEEE 18th International Conference on Nanotechnology (IEEE-NANO), Cork, Ireland, 23-26 July 2018; IEEE: Piscataway, NJ, USA, 2018; pp. 1-3. 